Editorials represent the opinions of the authors and not

necessarily those of the BMJ or BMA
EDITORIALS

For the full versions of these articles see bmj.com

\title{
Equitable access to health care
}

\section{We have adequate evidence to improve health services now in less resourced countries}

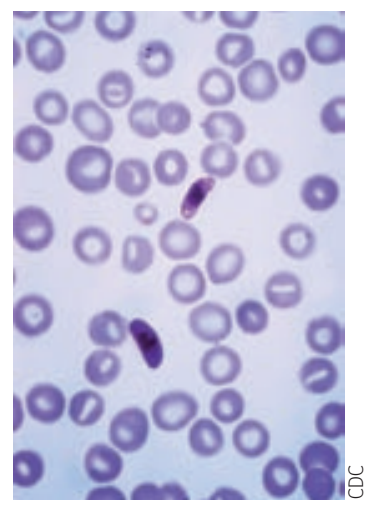

RESEARCH, pp 862, 873, 875

James K Tumwine professor,

Department of Paediatrics and

Child Health, Makerere University

Medical School, PO Box 7072,

Kampala, Uganda

jtumwine@imul.com

Competing interests: None

declared.

Provenance and peer review:

Commissioned; not externally

peer reviewed.

BMJ 2007;335:833-4

doi: 10.1136/bmj.39371.586076.80

This article was posted on bmj. com on 22 October 2007: http:// bmj.com/cgi/doi/10.1136/

bmj.39371.586076.80
As the world grapples with the problems of poverty and ill health, most people would agree that urgent action is needed to reduce the unacceptably high number of deaths of children living in resource constrained countries. ${ }^{1}$ Three studies in this week's $B M J$ provide evidence to improve health services in less resourced countries..$^{2-4}$ The first study, by Biai and colleagues, is a randomised controlled trial from Guinea Bissau in West Africa. They show that supervising healthcare workers to adhere to standard treatment protocols reduces mortality in children admitted to hospital with severe malaria. ${ }^{2}$ This may not seem surprising. What is surprising, though, and of major policy importance, is that a key part of this effective intervention was to provide a small financial incentive to health workers (equivalent to one month's rent).

Many agencies, including governments in countries in sub-Saharan Africa with less resources, have been reluctant to give financial incentives to their staff. They have opted instead for non-financial incentives such as acknowledging staff professionalism, offering career development and training, enforcing strict codes of conduct, and setting benchmarks for performance-all to no avail. ${ }^{5}$

In the 1980s and 1990s the policies of economic structural adjustment and health sector reform saw expenditure on health by many governments in the developing countries drastically reduced, at the behest of the World Bank and the International Monetary Fund. ${ }^{6}$ Although these policies are no longer in vogue, expenditure on health has not improved substantially, and the hospital wards in many of these countries are best described as pathetic. For example, in the paediatric ward in Guinea Bissau patients are diagnosed by an underpaid doctor who has to supplement his or her income through moonlighting. ${ }^{2}$ The patients might get the first emergency dose of the prescribed drugs from the hospital if they are lucky. Often however, the parents have to buy the drugs, intravenous cannula, and nasogastric tubes from private pharmacies that have mushroomed around the government run hospitals in the capital cities of these countries. Often, time is lost, and mortality in the first 24 hours is high. ${ }^{7}$

Several approaches have been tried to redress this situation-tackling the basic causes of ill health such as poverty, training of health staff on standardised treatment protocols, and increasing staff morale through sponsorship at training workshops where they can earn an extra income through per diems (daily allowances for accommodation and food). ${ }^{158}$ Some hospitals have introduced strict logging of arrival and departure times by staff. Campaigners have advocated the availability of free drugs at the point of care. Unfortunately few, if any, of these interventions seem to have led to clear reductions in mortality.

In the study by Biai and colleagues, all the patients received free medical kits for treating severe malaria and all the staff were trained and told to follow up the patients. In the intervention group, however, adherence to existing standards and case management guidelines and strict patient monitoring were ensured. ${ }^{2}$ In addition, this group of health workers was offered a financial incentive ( $\$ 50$ (£25; €35)/ month). The quality of heath care and subsequent better health of children on the paediatric wards depended not only on training, availability of free drugs and treatment kits, but also on these modest financial incentives. The extra pay was enough to enable staff to work efficiently, rather than moonlighting to pay rent and meet their obligations to their immediate and extended families.

The second study, by Bleich and colleagues, also reports on a financial intervention, and it finds that expansion of healthcare coverage to uninsured people in Mexico is associated with greater use of antihypertensive treatment. ${ }^{3}$ Both of these studies provide powerful evidence on ways to improve access to health care in places where poverty is prevalent. Meanwhile, Dorling and colleagues' study shows that income inequality-a measure of relative poverty-has a negative effect on overall health in less resourced as well as wealthy countries, especially for younger adults. ${ }^{4}$

Income inequality may be hard to tackle. But good evidence is now available for ministries of health and non-governmental organisations in less developed countries to tackle the urgent problems dogging health systems-inequitable access to care and poorly paid, demotivated, and overworked staff. Without concrete action it will be difficult to improve the effects of poverty on global health.

1 Sanders D, Todd C, Chopra M. Confronting Africa's heath crisis: more of the same will not be enough. BMJ 2005;331:755-8.

2 Biai S, Rodrigues A, Gomes M, Ribeiro I, Sodemann M, Alves F, et al. Reduced in-hospital mortality after improved management of children under 5 years admitted to hospital with malaria: 
randomised trial. BM/ 2007 doi: $10.1136 / \mathrm{bmj} .39345 .467813 .80$

3 Bleich SN, Cutler DM, Adams AS, Lozano R, Murray CJL. Impact of insurance and supply of health professionals on coverage of treatment for hypertension in Mexico: population based study. BM] 2007 doi: $10.1136 /$ bmj.39350.617616.BE.

4 Dorling D, Mitchell R, Pearce J. The global impact of income inequality on health by age: an observational study. BMJ 2007 doi: 10.1136/bmj.39349.507315.DE.

5 Mathauer I, Imhoff I. Health worker motivation in Africa: the role of non-financial incentives and human resource management tools.
Hum Resour Health 2006:4:24.

6 Tumwine J. Zimbabwe's success story in education and health: will it weather economic structural adjustment? J R Soc Health 1992;112:286-90.

7 Bachou H, Tumwine J, Mwadime R, Tylleskar T. Risk factors in hospital deaths in severely malnourished children in Kampala, Uganda. BMC Pediatr 2006;6:7.

8 Roenen C, Ferrinho P, Dormael M, Conceicao M, Van Lerberghe W. How African doctors make ends meet: an exploration. Trop Med Int Health 1997;2:127-35.

\title{
The role of national public health institutes in health infrastructure development
}

\author{
Science based and often relatively apolitical, they deserve $10 \%$ of \\ donors' funds
}

Jeffrey P Koplan director, Emory Global Health Institute, Emory University, Atlanta, GA 30322, USA jkoplan@emory.edu

Courtenay Dusenbury director, International Association of National Public Health Institutes (IANPHI) Sub-Secretariat, Emory Global Health Institute

\section{Pekka Jousilahti secretary} general, IANPHI Secretariat, National Public Health Institute (KTL), Fl-00300 Helsinki, Finland

Pekka Puska director general, National Public Health Institute (KTL)

Competing interests: All authors are fully salaried employees of government or academic institutions. PJ, JPK, and CD are partly supported by the Bill and Melinda Gates Foundation.

Provenance and peer review: Not commissioned; externally peer reviewed.

BMJ 2007;335:834-5 doi: 10.1136/bmj.39356.406377.BE

This article was posted on bmj. com on 22 October 2007: http:// bmj.com/cgi/doi/10.1136/

bmj.39356.406377.BE
Modern day challenges to public health systems include-as well as infectious and chronic diseasesthe need to improve environmental health, occupational health, and mental health; to reduce injuries; to strengthen systems for delivering public health services; and to prepare for unanticipated problems and emergencies, such as natural disasters and bioterrorism.

Public health services have developed in a less consistent manner than medical services in hospitals, clinics, and primary care. But, from 19th century pioneers of public health such as Farr, Chadwick, and Snow in England; Shattuck in the United States; and Frank, Villerme, and Virchow on the European continent, ${ }^{1}$ to Yen and Grant in Ding County, China, ${ }^{2}$ disciplines and skills have evolved into a set of recognised essential public health capacities. As defined by the Pan American Health Organization ${ }^{3}$ and the US Centers for Disease Control and Prevention (CDC), ${ }^{4}$ such capacities permit a nation-through its public health authorities-to recognise, measure, and tackle health challenges through population based interventions. ${ }^{3}$

Many countries find it useful to group target problems together and to cluster essential capacities under one roof-or at least under roofs whose buildings are in close organisational proximity. These national public health institutes provide focused, centralised leadership and coordination for public health in a country. They are generally quasi-governmental institutions, which are often affiliated with national ministries of health. Effective national public health institutes have adequate human, financial, and infrastructure support and good links with key organisations within the country and internationally.

The International Association of National Public Health Institutes (IANPHI; www.ianphi.org), founded in 2002 and now with 50 members, supports the development and strengthening of these institutes throughout the world. ${ }^{5}$ The association's mission is to strengthen existing national public health institutes and to create new ones by providing funded grants to support national priorities for the development of public health infrastructure. It is also a professional association for directors of national institutes, and it fosters leadership development and advocacy for public health.

National public health institutes allow countries to set and implement national priorities, respond to international regulations, develop human and physical capacity, and (in countries with low resources) ensure that donor funds are used in a coordinated manner to meet national public health priorities-a crucial problem in countries with multiple and fragmented donors. For example, in 2002, Vietnam received aid from 25 official bilateral donors, 19 official multilateral donors, and about 350 international non-governmental organisations, which funded more than 8000 development projects. ${ }^{6}$ Likewise, countries in sub-Saharan Africa typically receive aid from an average of 25 bilateral donors each year. ${ }^{7}$

National public health institutes often began with more narrow and circumscribed missions and roles (such as malaria control for the US Centers for Disease Control and Prevention), but many-including the Brazilian Fundação Oswaldo Cruz (FIOCRUZ), the Chinese Center for Disease Control and Prevention (China CDC), the Finnish National Public Health Institute (KTL), and the Netherlands National Institute of Public Health and the Environment (RIVM)-have grown in breadth and depth as public health functions and challenges have increased.

Some have their basis in international models and networks, such as the Pasteur Institute's facilities in Morocco, Vietnam, and elsewhere. Others, including those in Mexico, South Africa, Thailand, and the Czech Republic, have developed from national needs. In recent years, several institutes-including the UK Health Protection Agency, the Canadian Public Health Agency, and the Hong Kong Centre for Health Protection-have been created in the wake of major and dramatic public health crises that demanded an effective response.

National public health institutes permit the assembly of a critical mass of skills, disciplines, experience, and expertise. For example, tackling antibiotic resistance in a community requires not only laboratory microbiologists, 
epidemiologists, and statisticians but also health educators and communicators, infectious disease specialists, and others.

Even in nations with limited resources-where a fledgling institute may comprise only a handful of nurses, doctors, laboratory workers, and public health inspectors or sanitarians-such a cluster can be more effective when placed in a common unit and can serve as a building block towards more robust national capacity. Moreover, as a science based organisation, a national public health institute is often somewhat removed from the politics and pressures of a ministry of health. These institutes often engender a high level of trust and, in some cases, use donor funds more transparently and effectively. The framing of public health decisions through scientific knowledge, data, analysis, and evidence serves as a vital precondition for good decision making and policy setting. At the same time these institutes can also provide a centralised focus for implementing policies such as the new International Health Regulations. ${ }^{8} 9$

A coordinated approach to health services and public health systems is more effective than simply investing in thousands of vertical, unconnected, and uncoordinated programmes. ${ }^{10}$ But it needs adequate funding. We propose that donors of funds for specific diseases and other health problems in nations with low resources allocate $10 \%$ of their donations to the development of infrastructure in the host country, with special consideration for national public health institutes. Mechanisms for auditing and evaluating programmes should then be applied to both the programmatic and infrastructural components of these grants.

1 Porter R. The greatest benefit to mankind: a medical history of humanity. New York: WW Norton and Company, 1997.

2 Spence JD. The search for modern China. New York: WW Norton and Company, 1990

3 Pan American Health Organization. Public health in the Americas: conceptual renewal, performance assessment, and bases for action. Washington, DC: PAHO, 2002

4 Centers for Disease Control and Prevention. National public health performance standards program. Atlanta, GA: CDC, 1994. www.cdc. gov/od/ocphp/nphpsp.

5 Koplan JP, Puska P, Jousilahti P, Cahill K, Huttunen J; National Public Health Institute partners. Improving the world's health through national public health institutes. Bull World Health Organ 2005;83:154-7.

6 Acharya A, de Lima AF, Moore M. The proliferators: transactions costs and the value of aid. Brighton, UK: Institute of Development Studies, 2003.

7 World Bank. Global monitoring report 2005. Washington, DC: World Bank, 2005. http://siteresources.worldbank.org/ GLOBALMONITORINGEXT/Resources/complete.pdf.

8 World Health Assembly. Revision of the International Health Regulations, WHA58.3. Geneva:WHO, 2005. www.who.int/gb/ ebwha/pdf_files/WHA58/WHA58_3-en.pdf.

9 Rodier G, Greenspan AL, Hughes IM, Heymann DL. Global public health security. Emerg Infect Dis 2007;13:1447-52.

10 Jamison DT. Investing in health. In: Jamison DT, Breman JG, Measham AR, Alleyne G, Claeson M, eds. Disease control priorities in developing countries. 2nd ed. New York: Oxford University Press, 2006.

\section{Rapid tranquillisation in emergency psychiatric settings In resource poor settings, a sleeping patient is better than one who needs constant observation}

\section{RESEARCH, pp 865, 869}

\section{Chittaranjan Andrade}

professor and head of

department, Department of

Psychopharmacology, National Institute of Mental Health and

Neurosciences, Bangalore

560029 , India

andradec@gmail.com

Competing interests: None declared.

Provenance and peer review: Commissioned; not externally peer reviewed.

BMJ 2007;335:835-6 doi: 10.1136/bmj.39359.614387.80

This article was posted on bmj. com on 22 October 2007: http:// bmj.com/cgi/doi/10.1136/

bmj.39359.614387.80
Two randomised controlled trials in this week's $B M J$ assess the effectiveness of different combinations of drugs for tranquillising and sedating people who are violent or agitated as a result of psychiatric disorders. ${ }^{12}$ Both trials were undertaken in developing countries.

The first trial, by Raveendran and colleagues, was carried out in the emergency services of a general psychiatry department in a hospital in South India. It compared the tranquillising and sedative effects of a single intramuscular administration of either olanzapine $(10 \mathrm{mg})$ or a combination of haloperidol $(10 \mathrm{mg})$ plus promethazine $(50 \mathrm{mg})$ in 300 aggressive or agitated patients. The observation period lasted for four hours only and patients were followed up for just two weeks. This contrasts with most randomised controlled trials in psychiatry, which have treatment periods lasting for four to 12 weeks and can have several months of follow-up. The trial is important, however, because it looks at a neglected ${ }^{3}$ area-the early effects of treatment with parenteral antipsychotic drugs in patients who are violent or agitated. Without effective treatment these patients may harm themselves and their environment, ${ }^{3}$ and they are a heavy burden on resources in emergency psychiatry facilities.

Violent patients are usually psychotic and often receive antipsychotic drugs. In the Indian trial, 10\% of the participants were depressed, two thirds were manic, and the remainder had other forms of psychosis. At all five assessments during the four hour study significantly more people were asleep after the haloperidol-promethazine combination than with olanzapine (number needed to treat (NNT) ranged from 5 to 8 ). Whereas revisits by consultants $(\mathrm{NNT}=6)$ and the use of additional drugs $(\mathrm{NNT}=5)$ were less frequent with the combination, the need for physical restraint and the adverse effects of drugs did not differ significantly between the treatment groups. No patient experienced dystonia.

Clinicians are usually satisfied if drugs tranquillise a disturbed patient. The two treatment groups did not differ significantly in the combined outcome measure of being tranquil or asleep at 15 and 30 minutes. However, at one hour significantly more people taking the combination treatment were tranquil or asleep $(\mathrm{NNT}=19)$. Some people taking olanzapine needed additional drugs, after 
which the proportion of those tranquil or asleep in the two groups was once again similar. There is a clear take home message here-if being tranquil or asleep is the desired end point, intramuscular olanzapine is as good as intramuscular haloperidol plus promethazine if the doctor is willing to take a $20 \%$ chance of being called back an hour later to give another dose.

The National Institute for Health and Clinical Excellence (NICE) guideline ${ }^{4}$ describes a hierarchy of interventions for the emergency management of violent patients; parenteral tranquillisation with antipsychotic drugs is almost a last resort, and the goal of management is to induce calm, not sleep. Regrettably, these recommendations are impractical in most emergency medical settings in developing countries, where resources are strained by heavy patient loads and understaffing, and where a sleeping patient is better than one who needs constant observation to assess the need for tranquillisation. From the patient's perspective, being asleep is also less traumatic than being physically restrained. These considerations, and the lower cost, favour the combination of haloperidol-promethazine over olanzapine for the emergency management of violent patients in the developing world. However, although the combination is popular in some settings, ${ }^{5}$ the NICE guideline ${ }^{4}$ does not recommend it because of lack of safety data from the United Kingdom.

Treatment guidelines are seldom written with developing countries in mind, so the trial by Raveendran and colleagues ${ }^{1}$ offers useful guidance relevant to these settings. Importantly, the varied treatment outcomes assessed allow clinicians in other parts of the world to make choices on the basis of the outcome that is relevant to their own settings. Other strengths of the trial are that it assessed "real world" patients who were severely disturbed and who could not provide informed consent; almost all eligible patients were recruited; the outcome measures examined were clinically relevant; proxy measures were excluded; and nearly all patients completed the four hour study.

However questions remain. Dystonia is an important adverse effect of parenteral haloperidol. Although dystonia did not develop during the four hour observation period we are not told whether any patients experienced dystonia later, when the effect of promethazine wore off. Reassuringly, the second trial in this issue, which was conducted in $\mathrm{Brazil}^{2}$ but is similar to the Indian one, found that none of the 156 patients who received intramuscular haloperidol (5-10 mg) with promethazine $(25-50 \mathrm{mg})$ developed dystonia within 24 hours of treatment. In contrast, 10 of 160 patients who received only intramuscular haloperidol (5-10 mg) had dystonia.

The Brazilian study found that the combination of haloperidol-promethazine was more likely to tranquillise or induce sleep than haloperidol alone at 20 minutes (the two treatments did not differ in this or other measures at later assessments up to
24 hours). ${ }^{2}$ This suggests that at least part of the early benefit of the combination arises from the sedative action of promethazine. So, might a higher dose of intramuscular olanzapine or a combination of olanzapine and an oral or parenteral sedative have a safety-efficacy profile similar to that of the haloperidol-promethazine combination? We do not yet know, but the answer would interest those who do not wish to prescribe a neuroleptic.

Data from the United States ${ }^{6}$ and the $\mathrm{UK}^{7}$ suggest that, with regard to pragmatic long term outcomes in people with schizophrenia, at least some of the first generation antipsychotic drugs compare favourably with atypical antipsychotics. Concerns have been expressed about these conclusions. ${ }^{8}{ }^{9}$ Nevertheless, the results of Raveendran and colleagues' trial suggest that similar conclusions may also apply to pragmatic early outcomes in violent and agitated patients. ${ }^{8}{ }^{9}$ However, there is a caveat-the Brazilian trial reported three seizure events within 24 hours of the administration of haloperidol monotherapy (two events) or the haloperidol-promethazine combination (one event). ${ }^{2}$ Although no seizures were reported in the comparably large Indian trial, we should be mindful of the potential risk.

Rapid tranquillisation must not be confused with rapid neuroleptisation, which refers to treatment of a psychotic episode with the early administration of large doses of parenteral neuroleptics. Rapid neuroleptisation seeks to hasten recovery from psychosis, but it has not been shown to be effective for this purpose. ${ }^{10}$

1 Raveendran NS, Tharyan P, Alexander J, Adams CE; and the TRECIndia II Collaborative Group. Rapid tranquillisation in psychiatric emergency settings in India: pragmatic randomised controlled trial of intramuscular olanzapine versus intramuscular haloperidol plus promethazine. BMJ 2007 doi: 10.1136/bmj.39341.608519.BE.

2 Huf G, Coutinho ESF, Adams CE; TREC Collaborative Group. Rapid tranquillisation of violent or agitated people in psychiatric emergency settings: pragmatic randomised controlled trial of intramuscular haloperidol versus intramuscular haloperidol plus promethazine. BMJ 2007 doi: 10.1136/bmj.39339.448819.AE.

3 Andrade $C$. The risk of harm in mania and the very early time course of improvement: important but neglected variables in treatment research. Bipolar Disord 2004;6:446-7.

4 National Institute for Health and Clinical Excellence. Violence: the short-term management of disturbed/violent behaviour in in patient psychiatric settings and emergency departments. 2005. www.nice.org.uk/pdf/cg025niceguideline.pdf.

5 Huf G, da Silva Freire Coutinho E, Fagundes HM Jr, Oliveira ES, Lopez $J R$, Gewandszajder M, et al. Current practices in managing acutely disturbed patients at three hospitals in Rio de Janeiro-Brazil: a prevalence study. BMC Psychiatry 2002;2:4.

6 Lieberman JA, Stroup TS, McEvoy JP, Swartz MS, Rosenheck RA, Perkins DO, et al; for the Clinical Antipsychotic Trials of Intervention Effectiveness (CATIE) Investigators. Effectiveness of antipsychotic drugs in patients with chronic schizophrenia. N Engl J Med 2005;353:1209-23.

7 Jones PB, Barnes TRE, Davies L, Dunn G, Lloyd H, Hayhurst KP, et al. Randomized controlled trial of the effect on quality of life of secondvs first-generation antipsychotic drugs in schizophrenia: cost utility of the latest antipsychotic drugs in schizophrenia study (CUtLASS 1). Arch Gen Psychiatry 2006;63:1079-87.

8 Andrade C. Critical readings in psychiatry. Vol 3. Bombay: Pentacare, 2007.

9 Andrade C, Kharawala S. First- vs second-generation antipsychotic drugs in schizophrenia. Arch Gen Psychiatry 2007;64:978-9.

10 Coffman JA, Nasrallah HA, Lyskowski J, McCalley-Whitters M, Dunner FJ. Clinical effectiveness of oral and parenteral rapid neuroleptization. J Clin Psychiatry 1987;48:20-4. 
Gwen Adshead forensic

psychotherapist, Broadmoor Hospital, Crowthorne, Berkshire RG457EG

Gwen.adshead@wlmht.nhs.uk

Peter Fonagy professor,

Psychoanalysis Unit, University

College London, London WC1E 60T

Sameer P Sarkar forensic

psychiatrist, Berkshire

Competing interests: None declared.

Provenance and peer review: Commissioned; not externally peer reviewed

BMJ 2007;335:837 doi: 10.1136/bmj.39365.683877.BE

\section{Violence and gun crime}

\section{Protecting children and reducing social exclusion are the priorities}

The headlines about gun crime and violent crime in the United Kingdom are tragic and alarming-seven deaths of young people by October 2007 from gun crime and an apparent increase in violent crime generally. When combined with other news of gun related incidents, such as the shooting of Jean Charles De Menezes by a police officer in a London underground station, anxiety about the danger of guns is understandably high.

The statistics behind the headlines help to put the problem into context. Firearms offences in this country constitute $0.4 \%$ of all recorded crime; only $0.2 \%$ if airguns are excluded. The overall frequency of gun crime in the UK has been decreasing, and in 2005-6 the number of homicides involving firearms was 50 : the lowest for 10 years. ${ }^{1}$

Looking at homicide figures from an international perspective also helps reduce the collective sense of anxiety. In 2001, the average homicide rate internationally was $1.6 / 100000$ people ${ }^{2}$ which interestingly is the same as in England and Wales. The rate in Scotland, which has a total ban on guns, was 2.2. The rate in the United States is 5.6, but even this rate is much lower than that found in Estonia and Latvia (10.6) and Russia (22.1), and it pales into insignificance when compared with South Africa (51) and Colombia (62).

But 50 deaths is still 50 too many. Young people (16-29 years) are the second most likely group of people to be victims of homicide. ${ }^{3}$ Children under 16 are the group most likely to die as a result of homicide. They are usually killed by their parents or someone known to them, but in $21 \%$ of cases no suspect is identified. ${ }^{1}$ Firearms seem mainly to be used as a threat, to coerce compliance. Of course, the same could be said of knives, which are potentially just as lethal. The attraction of the gun is that it can be used from a safe distance, so the shooter is disconnected from the victim's suffering.

In 2006, a Home Office report reviewed the use of illegal firearms in 80 young men convicted of acts of violence. ${ }^{4}$ It found that gun crime by young men seems to be facilitated by criminal opportunities (usually drug related) and reinforced by visibly "successful" criminals. Gang membership provides opportunities for conflict, which often starts in nightclubs or other social spaces. The report does not, however, comment on the fact that most high profile shootings (like Dunblane and Hungerford) are not carried out by young people, and have nothing to do with gangs, drugs, or a vision of successful criminality.

What the Home Office statistics and the report suggest is a picture of socially isolated young men, looking for an identity. Of the 80 men studied, 59 came from disrupted family backgrounds- 35 from single parent families, presumably with no positive male role models. Just over half had been excluded from school and so were disconnected from the positive influence of peers and teachers. Such disconnected young men may be highly fearful, or highly fearless-both states of mind that are a defence against negative affects like shame, humiliation, anger, and distress. Such affects make violence more likely, especially if the young person lacks the capacity to mentalise (the process of thinking about our feelings and examining what we feel about our thoughts) and regulate these feelings. ${ }^{5}$ A young man who cannot mentalise negative feelings is much more likely to act them out. Failure to mentalise is unlikely to be the only explanation for gun violence, but improving mentalising skills may help people to think more about why they want a gun.

How can gun crime rates be changed? The debate about access to guns remains highly political, and commentators tend to have polarised views. International evidence shows a close correlation between gun ownership and rates of suicide and homicide. ${ }^{6}$ Reducing access to guns should reduce both these forms of violence; however, a US study showed that legislation relating to handgun sales had little effect on homicide and suicide rates, except for suicides in people over $55 .^{7}$ In the UK, ownership of handguns has been restricted since 1997, yet fatal gun crimes still occur. One possible inference might be that guns themselves are not risky, but the intention to use them is.

Improving the welfare of young people at risk of acting violently might be more fruitful. School programmes include Peaceful Schools in the US ${ }^{8}$ and Safer Schools Partnerships in the UK. ${ }^{9}$ An excellent document published by the Youth Justice Board ${ }^{10}$ emphasises both risk and protective factors, and it describes possible interventions. Many of the risk factors for later violence are linked to being raised in a disrupted and abusive family, because this experience prevents children forming attachment relationships and negatively affects the capacity to think and mentalise. ${ }^{11}$ Yet, most of the interventions relate to school and community groups-hardly any interventions target abusive parents or families. No services exist for parents who pose a danger to their children, in sharp contrast to the development of services for men who are dangerous to children in general. ${ }^{12}$

Overall, reducing social exclusion and deprivation and increasing the protection of children may be more effective than focusing on gun control alone. Certain initiatives can improve young people's mental health, which in turn will improve their capacity to mentalise and reach out to others when they are in distress. These require investment and attention to a small group of children who are at risk of acting violently, rather than the much bigger group of children who will never pose such a risk. Early identification of children who are most at risk would help to reduce the development of a paranoid and dangerous mindset that makes a gun one of the easier answers to a conflict. As the National Rifle Association reminds us, "Guns don't kill, it's the finger on the trigger."

All references are on bmi.com 


\section{Providing care closer to home}

\section{The strategy is popular with patients but questions about cost and quality remain}

\begin{abstract}
Chris Salisbury professor of
primary health care

Sarah Purdy consultant senior

lecturer in primary health care,

Academic Unit of Primary Health

Care, University of Bristol, Bristo

BS8 2AA

c.salisbury@bristol.ac.uk
\end{abstract}

Competing interests: None declared.

Provenance and peer review: Commissioned; not externally peer reviewed.

BMJ 2007;335:838 doi: 10.1136/bmj.39371.523171.80
The 2006 National Health Service (NHS) white paper, Our health, our care, our say, set out a strategy to provide more services in the community, closer to people's homes. ${ }^{1}$ The report of the evaluation has just been published, ${ }^{2}$ along with a report from the specialties involved. ${ }^{3}$ The strategy was based on international experience that moving care from large hospitals to smaller local sites improves patient satisfaction and outcomes and is more cost effective. The scheme involves new and more integrated care pathways, polyclinics that provide a wide range of diagnostic and therapeutic services, ${ }^{4}$ and renewed investment in community hospitals. Plurality of services, and the system of "payment by results" by which money follows patients, should enhance patient choice and incentivise quality and value. ${ }^{5}$

The white paper included a commitment to evaluate the strategy in 30 "closer to home" demonstration sites in six specialties: dermatology; ear, nose, and throat; general surgery; gynaecology; orthopaedics; and urology. The services provided by the demonstration sites varied, from home based catheter care to day case surgery. Many involved general practitioners, nurses, or other health professionals working as practitioners with special interests. Implementation of the demonstration sites and their effect on access to care, quality of care, and costs were evaluated.

What can we learn from these reports? Developments were often driven by the enthusiasm of local clinicians and the availability of a suitable venue, as much as by healthcare needs. Not surprisingly, sites that had local champions and that consulted widely with stakeholders found it easiest to establish services. Some sites creatively redesigned services to break down traditional barriers between primary and secondary care. The aim of improving patient satisfaction appears to have been achieved. Patients found the new local services more convenient, they experienced shorter waiting times, and they were happy with the quality of care they received.

Drawing conclusions about cost effectiveness is more problematic. Under payment by results, hospitals are paid using a fixed national tariff, which is based on an estimate of the average cost of providing care within broad categories such as general surgery outpatients. ${ }^{6}$ A standard tariff was used to encourage providers to focus on quality and quantity of referrals rather than price. ${ }^{5}$ However, many of the demonstration sites provided care for simple procedures at well below the tariff. This does not mean that these demonstration sites necessarily represent better value, as it is important to distinguish between the cost of providing a service and the price hospitals have to charge. Several studies have shown that care in the community is generally more costly than hospital based care. ${ }^{7-9}$ Diverting low cost cases, on which hospitals make a profit, while leaving them with the complex and expensive cases, on which they make a loss, is unsustainable.

In addition, most demonstration sites were designed to increase capacity so that waiting lists could be cut; this represents an additional cost. Savings can be made only by disinvesting in hospitals, but if the marginal cost of providing low complexity care in hospitals is less than the cost of establishing new services in the community this may not ultimately be good value. Finally, the increased capacity, accessibility, and popularity of closer to home services are likely to lead to an increase in demand, particularly if (as in some cases) these services provide direct access for patients without referral from a general practitioner. Therefore, this policy could actually increase total costs to the NHS.

The third aim of the policy was to improve outcomes for people. Although the evaluators asked patients and staff about quality of care, no objective measures of quality, outcome, or competency were available. This is worrying, as care is being transferred from one type of practitioner to another and from centralised units to smaller peripheral centres. Both hospital consultants and some of the community practitioners expressed concern about this matter. In particular, some nurses were worried about their lack of training for the new responsibilities they had been given. Training needs and accreditation criteria have now been defined for general practitioners and pharmacists, ${ }^{10}$ but for nurses this is an ongoing problem that needs to be resolved, and robust arrangements to audit quality and outcomes are essential.

Finally, a tension exists between promoting patient choice and providing value for money. The demonstration sites seemed to be designed to increase choice for commissioners rather than for patients, because they often involved triage of patients referred for secondary care. Some patients prefer to attend hospitals, ${ }^{11}$ and it will be interesting to see whether commissioners allow this choice to be exercised if the price of hospital care is higher.

Despite these caveats, the aim of providing care closer to home is laudable. It could potentially offer high quality and accessible care in a way that patients prefer. The vision set out in the white paper is radical and could have important implications for the future shape of health care in England. However, most of the demonstration sites are currently of small scale, and the evaluation provides limited evidence about the costs and benefits of the policy. It highlights the need for careful attention to implementation, costs, quality, and training as the policy is rolled out more widely.

All references are on bmj.com 